\section{Big Five personality traits impact on entrepreneurial intention: the mediating role of entrepreneurial alertness}

Big Five personality traits

\author{
Mohammad Suleiman Awwad and
}

Rana Mohammad Najati Al-Aseer

Department of Business, Mutah University, Al-Karak, Jordan
Received 4 September 2020 Revised 9 January 2021 Accepted 22 March 2021

\begin{abstract}
Purpose - The purpose of this study is to investigate the impact of the Big Five personality traits on the entrepreneurial intentions of undergrad university students in Jordan. It further investigates the mediating role of entrepreneurial alertness.

Design/methodology/approach - A quantitative survey method was conducted with a convenience sample of Jordanian university students. A total of 323 valid questionnaires were received and analyzed. A structural equation modeling with partial least square (PLS) is used to analyze data.

Findings - Results revealed that conscientiousness, openness and alertness were associated with entrepreneurial intention. Extraversion and openness were associated with alertness, while agreeableness and neuroticism were unrelated to either outcome. Finally, alertness mediates the relationship between extraversion and openness with entrepreneurial intention.

Originality/value - There is a lack of previous studies investigating the relationship between the Big Five personality traits and students' entrepreneurial intentions in Jordan, particularly the role of mediating variables in this relationship. This study is considered the first one that examined the mediating role of entrepreneurial alertness in the relationship between personality traits and entrepreneurial intentions.
\end{abstract}

Keywords Jordan, Entrepreneurial intention, Big Five personality traits, Entrepreneurial alertness, Universities students

Paper type Research paper

\section{Introduction}

The concept of entrepreneurship has received increasing attention in various countries globally, especially in developing countries, which suffer from several problems that hinder economic growth. Entrepreneurship is essential in addressing economic problems, such as unemployment, new wealth creation, job creation, stabilizing society, increasing industrial competition and economic development. Therefore, entrepreneurship has received much attention from governments and decision-makers to understand encouraging and directing new workforce, e.g. undergraduate students, toward entrepreneurial activities to tackle the

(C) Mohammad Suleiman Awwad and Rana Mohammad Najati Al-Aseer. Published in Asia Pacific Journal of Innovation and Entrepreneurship. Published by Emerald Publishing Limited. This article is published under the Creative Commons Attribution (CC BY 4.0) licence. Anyone may reproduce, distribute, translate and create derivative works of this article (for both commercial and non-commercial purposes), subject to full attribution to the original publication and authors. The full terms of this licence may be seen at http://creativecommons.org/licences/by/4.0/legalcode

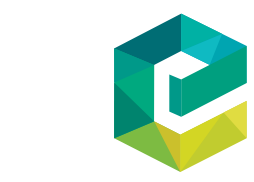


APJIE 15,1

economic problems and their negative consequences (Merrill et al., 2008; Kim, 2018). Many researchers have begun to determine and examine the factors that can predict entrepreneurial orientation to achieve this. One of the most dominant streams of research regarding predicting entrepreneurial intention was personality traits. Research on the relationship between personality and entrepreneurship began several decades ago, specifically during the last third of the twentieth century (Kerr et al., 2018).

To further understand the relationship between personality and entrepreneurship, researchers began to study the influence of general personality traits (Big Five personality traits) or specific personality traits (i.e. the need for achievement) on an individual's intention to start a new business or differences between entrepreneurs and managers (Zhao et al., 2010). Personality traits are suggested to be a more reliable influence on becoming an entrepreneur (Wang et al., 2016). There was a widespread belief that there was no consistent relationship between personality and entrepreneurship. Previous studies have indicated mixed results (Zhao et al., 2010). Several researchers have attempted to explain this variation in results by investigating mediating variables' impact (Woo, 2018; Farrukh et al., 2018). Entrepreneurial alertness, which can detect business opportunities, is another essential construct underlying intrapreneurship and was first defined by Kirzner (1999). Alertness helps individuals accumulate and trigger sniffing ability, which makes them capable of identifying gaps in the market that others have overlooked (Kirzner, 1999).

However, most of the literature is related to the relationship between Big Five personality traits and entrepreneurship conducted in developed countries and did not receive enough attention in developing countries, such as Jordan (Alkhatib et al., 2020). According to Knoema (2019), the global entrepreneurship index indicates that Jordan's ranking is (64) between (136) country around the world, with an entrepreneurship index of 29.4. This indicator is good and emphasizes the importance of entrepreneurship in Jordan, and there is a need to maintain and increase this indicator's level. Therefore, this study investigates the relationship between the Big Five personality traits and entrepreneurial intention and how entrepreneurial alertness mediates this relationship.

\section{Literature review and hypotheses development Personality traits}

A personality trait can be described as a consistent individual reaction caused by external conditions. Personality theorists have argued that the prediction of a person's behavior can be made using their personality. Based on the findings presented by several meta-analyses, it is generally believed that an individual's success as an entrepreneur depends on their personality traits because traits determine a person's behavior and decision-making, thereby influencing success. According to Ciavarella et al. (2004), entrepreneurs who possess powerful traits related to high performance are more likely to run their businesses in the long term. Possession of certain personality traits makes one enjoy engaging in entrepreneurship activities as they find those activities fulfilling and satisfying. However, others who lack certain traits linked to entrepreneurship success might lack the desire to continue engaging in entrepreneurship activities once they are faced with a significant setback in their first projects. Some researchers (Goldberg, 1993) have argued that the Big Five personality traits can be used to express almost all of an individual's personality because of the scale's stability by which the Big Five personality traits are measured. Also, the Big Five personality traits can be used to assess an individual's suitability to entrepreneurship (Zhao et al., 2010). 
The intention is an intellectual state, or state of mind, in which people become motivated to focus on a particular goal (Chhabra et al., 2020). Thus, it is crucial to understand the role played by intention in the entrepreneurial journey. According to Verheul et al. (2012), the understanding of the concept of entrepreneurial intention is essential in determining the underlying motives for the process of entrepreneurship. Explorations of various studies (Saeed et al., 2013; Miralles et al., 2016) have also revealed that a successful business enterprise formation depends on the intention.

\section{Entrepreneurial alertness}

Although researchers have studied several entrepreneurship research topics, scholars have diverted more attention to why some people can perceive new opportunities and take necessary actions toward those opportunities. People with good entrepreneurial alertness can explore various opportunities and change their behaviors as determined by the new conditions. Entrepreneurially alert people can also use their creativity and imagination to identify potential challenges even when there is little clue to the problem (Tang et al., 2012). Van Gelderen et al. (2006) said that a person's entrepreneurial alertness strengthens his/her entrepreneurial intention, thereby motivating them to transform ideas into new businesses.

Extraverts are social individuals; they possess more confidence and skill in social interactions than others. Extraversion captures the extent to which an individual is comfortable in building social networks. Thus, extraverts are more likely to become successful entrepreneurs because there is a link between extraversion traits: including enthusiasm, assertiveness, social, outgoing, warm, talkative and energy and attributes of entrepreneurship. Scholars such as Zhao et al. (2010) have claimed that building social and professional networks, communication of vision and enthusiasm and negotiating deals are the essential leadership characteristics required by entrepreneurs. Individuals considered to have a greater degree of extraversion are usually friendly, social, energetic and active participants capable of dominating in social settings. Entrepreneurship seems more appealing and captivating for many individuals compared to traditional means of managing the business. As such, it is more stimulating to the extraverts who are optimistic about securing a better future. Based on the above, the researchers propose the following hypotheses:

\section{H1. Extraversion has a significant impact on entrepreneurial intention.}

H2. Extraversion has a significant impact on entrepreneurial alertness.

Agreeableness focuses on the quality of relationships through trust and cooperation. Individuals with higher agreeableness possess such traits as a courtesy, cooperation, consideration and flexibility. Scholars have greatly differed on the impact or extent to which the trait of agreeableness contributes to success in entrepreneurship. Some scholars, such as Singh and DeNoble (2003), argue that entrepreneurs with higher agreeableness are busier with social work than private businesses. Singh and DeNoble (2003) believe that people with high agreeableness engage in social work because it benefits others, unlike private business ventures.

On the contrary, some scholars also believe that high agreeableness is necessary for an entrepreneur to start a business venture. For instance, Ciavarella et al. (2004) explained that entrepreneurs could increase their businesses' profitability by creating several loyal clients by establishing trust and being courteous with customers. As a result, entrepreneurs with 
APJIE 15,1

high agreeableness are more likely to grow small businesses into big corporate entities. Based on the above, the researchers propose the following hypotheses:

H3. Agreeableness has a significant impact on entrepreneurial intention.

H4. Agreeableness has a significant impact on entrepreneurial alertness.

Various researchers, including Ciavarella et al. (2004) and Zhao et al. (2010), argued that the trait of conscientiousness defines a person's degree of achievement, planning, organization, job motivation, obligation toward others and perseverance. Researchers have generally concluded that conscientiousness is a measure of the reliability of an individual. For instance, Barrick et al. (2001) stated that conscientiousness was the most reliable personality indicator in employee performance across different professions. Entrepreneurship requires patience, hard work and a set of goals. Considering the assumption postulating that individuals are attracted to careers that resonate with their personality traits, conscientious persons will venture to entrepreneurship. According to Barrick et al. (2001), conscientious people are success-oriented, determined and highly motivated. Besides, they possess core traits that are required for success in entrepreneurship. Entrepreneurs acquire a sense of alertness through a cognitive process. Cognitive development characterizes learning capabilities and levels of experience among individuals. With the cognitive process, individuals develop knowledge-based characteristics, which define one's idiosyncratic or characteristic. Conscientious individuals are driven, determined and focus on acquiring useful knowledge and information. Thus, they are alert to changes in a particular setting. Based on the above, the researchers propose the following hypotheses:

H5. Conscientiousness has a significant impact on entrepreneurial intention.

H6. Conscientiousness has a significant impact on entrepreneurial alertness.

Neuroticism captures people's stress management approaches and illustrates the difference between different people in adjusting to a situation. According to Costa and McCrae (1992), people with high neuroticism tend to show mood swings, low self-esteem, depression, impulsiveness and self-consciousness. Barrick et al. (2001) stated that some of the common traits of people with high neuroticism include feeling depressed, being anxious, getting angry, emotionally insecure and worried and feeling embarrassed. Fiske et al. (2010) argued that highly neurotic individuals regard minor frustrations as hopelessly difficult and ordinary situations as threatening. Therefore, high neuroticism negatively affects an individual's entrepreneurial behavior because most highly neurotic individuals are prone to stress, generally worried and emotionally volatile. Popular literature presents entrepreneurs as optimistic individuals who are steady when faced with social pressure, uncertainty or stress. Entrepreneurs are always ready to take the emotional and physical burden and move even in situations where other people could be discouraged by self-doubt (Zhao et al., 2010). Based on the above, the researchers propose the following hypotheses:

H7. Neuroticism has a significant impact on entrepreneurial intention.

H8. Neuroticism has a significant impact on entrepreneurial alertness.

The trait of openness to experience captures the intellectual curiosity, creativity and imagination of an individual and is often associated with recognizing opportunities (Ciavarella et al., 2004). Openness can describe an individual's fascination with novelty and their range of interests. Creativity is important in entrepreneurship because creative 
entrepreneurs use innovative approaches to solve problems facing them. For instance, Ciavarella et al. (2004) explained that external factors affecting businesses are dynamic and require the entrepreneurs to pursue new knowledge and engage in innovative thinking to come up with effective strategies for dealing with external factors. Creativity is an essential trait in entrepreneurship, helping individuals introduce innovative solutions to existing problems. According to Quan (2012), background knowledge contributes significantly to thoughtful intention to startup. Based on the above, the researchers propose the following hypotheses:

H9. Openness to experience has a significant impact on entrepreneurial intention.

H1O. Openness to experience has a significant impact on entrepreneurial alertness.

Alertness concerns individuals' understanding, driven by beliefs about the social world. Some researchers (Kaish and Gilad, 1991) have demonstrated a positive relationship between entrepreneurial alertness and entrepreneurial intention. A recent study conducted by Lim et al. (2017) investigated how entrepreneurial alertness' mediating role affects entrepreneurial intention and discovered a significant relationship between entrepreneurial alertness and entrepreneurial intention. Kaish and Gilad (1991) found out that alert entrepreneurs are avid information gatherers and opportunistic too. Based on the above, the researchers propose the following hypotheses:

H11. Entrepreneurial alertness has a significant impact on entrepreneurial intention.

Personality traits can affect the individual ability to identify opportunities that others ignore easily and consequently influence one's entrepreneurial alertness (Huang, 2016). In other words, personality traits will affect entrepreneurs' recognition, choices and judgment of opportunity (Yan et al., 2018). On the other hand, entrepreneurial alertness directly influences entrepreneurial intention because entrepreneurial alertness develops the recognition of opportunity and judgment identification of individuals with business intent (Lu and Wang, 2018). In other words, personality traits affect entrepreneurial alertness, which in turn affects entrepreneurial intention. Based on the above, the researchers propose the following hypotheses:

H12a. Entrepreneurship alertness mediates the relationship between extraversion and entrepreneurship intention.

$H 12 b$. Entrepreneurship alertness mediates the relationship between agreeableness and entrepreneurship intention.

H12c. Entrepreneurship alertness mediates the relationship between conscientiousness and entrepreneurship intention.

H12d. Entrepreneurship alertness mediates the relationship between neuroticism and entrepreneurship intention.

H12e. Entrepreneurship alertness mediates the relationship between openness to experience and entrepreneurship intention.

The conceptual model (Figure 1) of this research describes the relationship between the Big Five personality traits and entrepreneurial intention through the mediating impact of entrepreneurial alertness. The researcher built his model in this way to make a new contribution to the current literature. Using entrepreneurial alertness as a mediator variable 


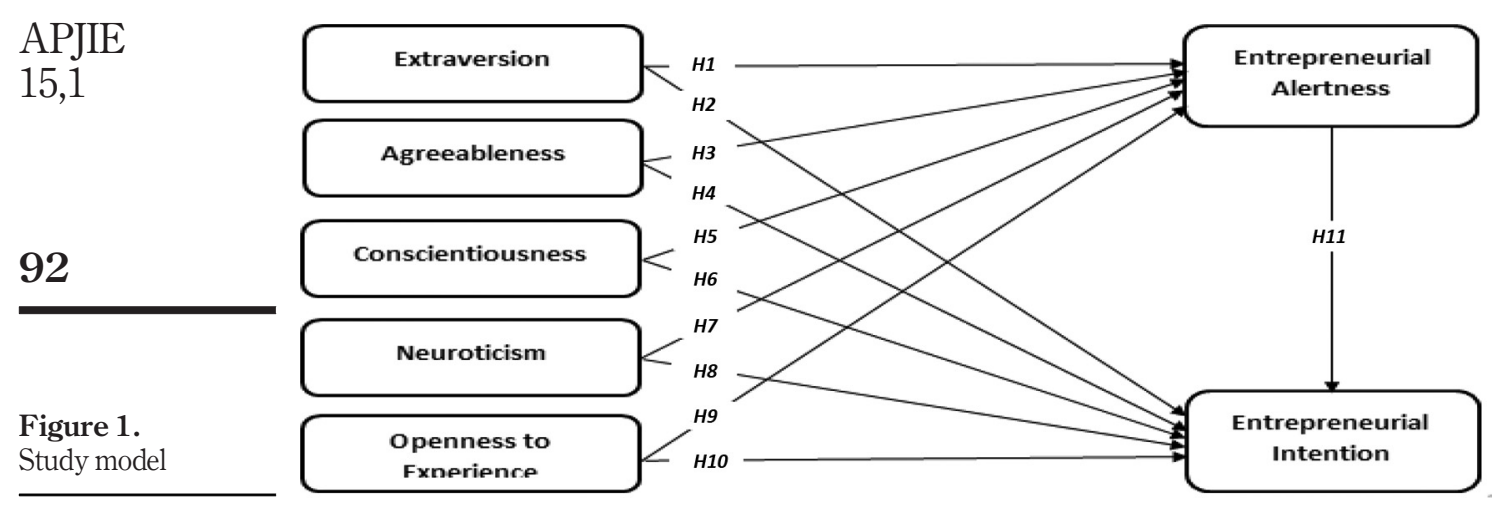

enables the researcher to investigate new sights and open new discussions that contributed to enriching the literature in this area.

\section{Methodology}

This study used a questionnaire survey based on the conceptual framework to gather responses from the sampled individuals. A descriptive and quantitative research design, with a deductive approach, was used to assess the characteristics and nature of the five major personality traits and how they impact the degree of alertness and intention of entrepreneurs.

\section{Population and sample}

This study covers a wide geographical area, with data collected from Jordanian university students. Following the guidelines (Hair et al., 2017), the appropriate sample size will be 384 students. Because of time and effort constraints and the lack of a comprehensive sampling frame, the sampling procedure will be done conveniently to ensure that adequate data are collected. From the 384 surveys distributed to the sampled students, 323 completed questionnaires were received, representing a response rate of $84 \%$.

\section{Measurement tool}

Using the literature and findings from previous studies, we designed questionnaires to gather appropriate hypothesis testing data. The definitions used in previous studies for the variables were adopted in this study. However, certain modifications were adopted to enhance the suitability of the definitions used in the analysis of the underlying relationship (Table 1).

Personal characteristics data analysis

The main characteristics of the study sample are summarized in Table 2.

\section{Measurement tool reliability}

The first step to assess the measuring tool's reliability is to examine the items loading on the variable that is set to measure it. The loading must be (0.70) or higher (Hair et al., 2017). As shown in Table 3 and Figure 2, the results show that the lowest value loaded on the corresponding factor was (0.700), which is equivalent to the minimum level. 
The next step is to examine reliability through composite reliability (CR) and Cronbach's alpha. Consequently, as mentioned in the prior studies, the acceptable minimum value for CR is (0.60-0.70) and Cronbach's alpha is (0.70) (Hair et al., 2017). Results in Table 3 show that the values of $\mathrm{CR}$ and Cronbach's alpha for each variable were much greater than the acceptable minimum level, which would further specify a high internal consistency in the measurement tool.

\section{Measurement tool validity}

There are two kinds of validity tests performed on the measurement instrument, namely, discriminant validity and convergent validity. Convergent validity tested using the average variance extracted (AVE). The acceptable level for AVE must be either 0.50 or above (Hair et al., 2017). Results in Table 3 show that AVE's values were higher than the acceptable minimum value. To examine the discriminant validity, the square root of AVE values must be considerably greater than the highest correlation coefficient of this variable with any other variables (Hair et al., 2017).

Results in Table 4 show that the values of the square root of AVE (on the diagonal line) were higher than the correlation coefficient of this variable with any other variables. These results indicate a high discriminant and convergent validity of the measurement tool.

\begin{tabular}{llll}
\hline Term & Definition & Source \\
\hline Extraversion & Sociable, forceful, energetic, adventurous, etc. & Goldberg (1993) & \\
Agreeableness & Forgiving, warm, compliance, etc. & Goldberg (1993) \\
Conscientiousness & Organized, dutiful, not impulsive, etc. & Goldberg (1993) \\
Neuroticism & Tense, irritable, depressed, shy, etc. & Goldberg (1993) & \\
Openness & Curious, imaginative, unconventional, etc. & Goldberg (1993) & Zhao et al. (2010) \\
Entrepreneurial & Ready to make anything to become an entrepreneur & Table 1. \\
intention & Opportunities seeker, information collector transform the problem & Tang et al. (2012) & $\begin{array}{r}\text { Operational } \\
\text { Entrepreneurial } \\
\text { alertness }\end{array}$ \\
\hline
\end{tabular}

\begin{tabular}{lcrr}
\hline & Frequency & $(\%)$ & \\
\hline Gender & & & \\
Male & 129 & 39.9 & \\
Female & 194 & 60.1 & \\
GPA & & 29.7 & \\
Excellent & 96 & 39.0 & Table 2. \\
Very good & 126 & 26.0 & Personal \\
Good & 84 & 5.3 & characteristics of \\
Satisfactory & 17 & 69.0 & respondents \\
Major & & 31.0 & \\
Humanity & 223 & &
\end{tabular}




\section{APJIE \\ 15,1}

94

Conscientiousness

Extraversion

\begin{tabular}{l} 
Variable \\
\hline Agreeableness \\
Conscientiousness
\end{tabular}

Table 3.

Measurement reliability test

\begin{tabular}{|c|c|c|c|c|c|c|}
\hline Extraversion & $\begin{array}{l}\text { EXTR1 } \\
\text { EXTR2 } \\
\text { EXTR3 } \\
\text { EXTR4 } \\
\text { EXTR5 }\end{array}$ & $\begin{array}{l}0.873 \\
0.866 \\
0.866 \\
0.857 \\
0.855\end{array}$ & 0.745 & 0.936 & - & 0.915 \\
\hline Neuroticism & $\begin{array}{l}\text { NEUR1 } \\
\text { NEUR2 } \\
\text { NEUR3 } \\
\text { NEUR4 } \\
\text { NEUR5 }\end{array}$ & $\begin{array}{l}0.889 \\
0.870 \\
0.966 \\
0.817 \\
0.832\end{array}$ & 0.768 & 0.943 & - & 0.942 \\
\hline Openness to experience & $\begin{array}{l}\text { OPEN1 } \\
\text { OPEN2 } \\
\text { OPEN3 } \\
\text { OPEN4 } \\
\text { OPEN5 }\end{array}$ & $\begin{array}{l}0.850 \\
0.841 \\
0.805 \\
0.857 \\
0.863\end{array}$ & 0.712 & 0.925 & - & 0.899 \\
\hline Entrepreneurial alertness & $\begin{array}{l}\text { ALERT1 } \\
\text { ALERT3 } \\
\text { ALERT4 } \\
\text { ALERT5 } \\
\text { ALRET2 }\end{array}$ & $\begin{array}{l}0.862 \\
0.909 \\
0.903 \\
0.894 \\
0.875\end{array}$ & 0.790 & 0.950 & 0.186 & 0.934 \\
\hline Entrepreneurship intention & $\begin{array}{l}\text { ENTR1 } \\
\text { ENTR2 } \\
\text { ENTR3 } \\
\text { ENTR4 } \\
\text { ENTR5 } \\
\text { ENTR6 }\end{array}$ & $\begin{array}{l}0.859 \\
0.858 \\
0.865 \\
0.865 \\
0.866 \\
0.872\end{array}$ & 0.747 & 0.947 & 0.803 & 0.932 \\
\hline
\end{tabular}

\section{Results}

Figure 3 and Table 5 show the results of the structural model test. The significance and relevance of the path coefficients had been estimated. The indirect impact that the independent variables have on the dependent variables was measured through the mediating variable.

\section{Discussion}

When the students were asked whether they seriously considered becoming entrepreneurs, the results indicated a high percentage $(69 \%)$ of them who are seriously considering becoming entrepreneurs as an option for professional development compared to other options such as working in private or public sectors. This high percentage led to whether the results are because of the sample's personality traits or not? 


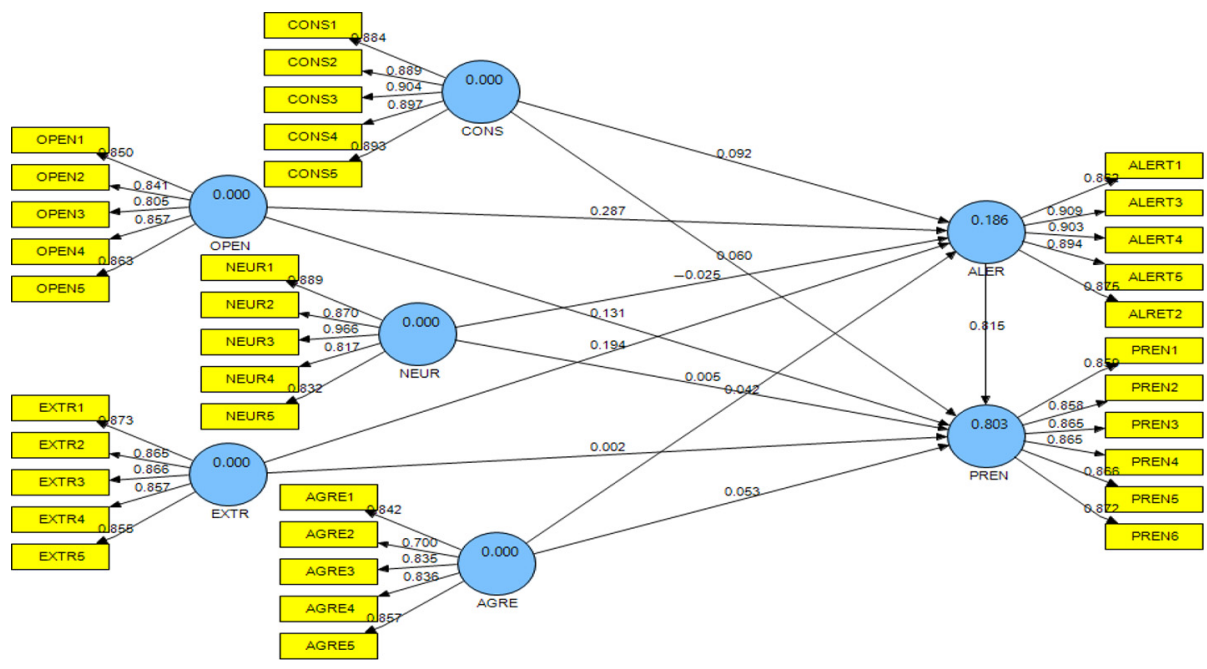

Big Five personality traits

\section{5}

Figure 2.

Measurement model

\begin{tabular}{lrrrrrrrr}
\hline Variables & AGRE & ALER & CONS & EXTRA & EUR & OPEN & ENTR & \\
\hline Agreeableness & 0.816 & - & - & - & - & - & - & \\
Entrepreneurial alertness & 0.150 & 0.889 & - & - & - & - & - & \\
Conscientiousness & 0.259 & 0.188 & 0.893 & - & - & - & - & Table 4. \\
Extraversion & 0.185 & 0.300 & 0.217 & 0.863 & - & - & - & Square root of AVE \\
Neuroticism & -0.090 & -0.046 & -0.126 & -0.058 & 0.876 & - & - & and correlation \\
Openness to experience & 0.159 & 0.358 & 0.139 & 0.270 & 0.020 & 0.844 & - & coefficients \\
Entrepreneurship intention & 0.211 & 0.882 & 0.245 & 0.305 & -0.042 & 0.440 & 0.864 & \\
\hline
\end{tabular}

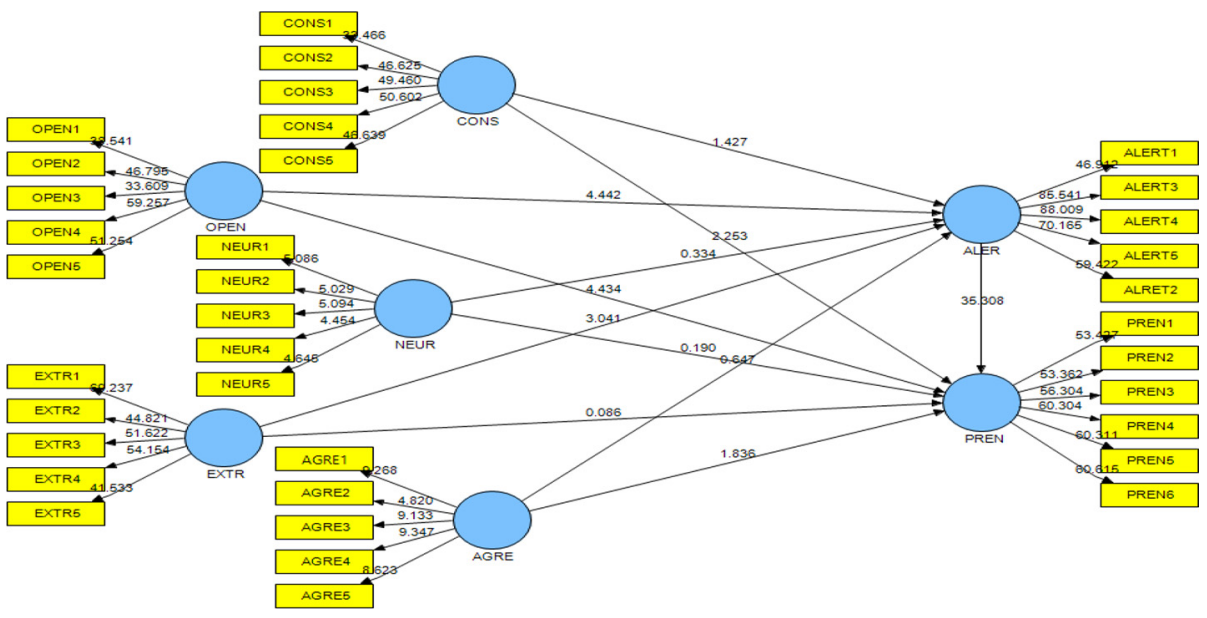

Figure 3. Structural model results 


\begin{tabular}{|c|c|c|c|}
\hline \multirow{6}{*}{$\begin{array}{l}\text { APJIE } \\
15,1\end{array}$} & Hypothesis & T Statistic & Sig \\
\hline & $H 1:$ Extraversion $\rightarrow$ Intention & 0.086 & 0.931 \\
\hline & H2: Extraversion $\rightarrow$ Entrepreneurial alertness & 3.041 & $0.003^{* *}$ \\
\hline & H3: Agreeableness $\rightarrow$ Intention & 1.836 & 0.069 \\
\hline & H4: Agreeableness $\rightarrow$ Alertness & 0.647 & 0.519 \\
\hline & H5: Conscientiousness $\rightarrow$ Intention & 2.253 & $0.026^{*}$ \\
\hline \multirow[t]{9}{*}{96} & H6: Conscientiousness $\rightarrow$ Alertness & 1.428 & 0.156 \\
\hline & $H 7:$ Neuroticism $\rightarrow$ Intention & 0.190 & 0.850 \\
\hline & H8: Neuroticism $\rightarrow$ Alertness & 0.334 & 0.739 \\
\hline & H9: Openness $\rightarrow$ Intention & 4.434 & $0.000^{* *}$ \\
\hline & H1O: Openness $\rightarrow$ Alertness & 4.442 & $0.000^{* *}$ \\
\hline & H11: Alertness $\rightarrow$ Intention & 35.308 & $0.000 * *$ \\
\hline & H12a: Extraversion $\rightarrow$ Alertness $\rightarrow$ Intention & 3.020 & $0.003^{* *}$ \\
\hline & H12b: Agreeableness $\rightarrow$ Alertness $\rightarrow$ Intention & 0.646 & 0.518 \\
\hline & H12c: Conscientiousness $\rightarrow$ Alertness $\rightarrow$ Intention & 1.436 & 0.151 \\
\hline \multirow{3}{*}{$\begin{array}{l}\text { Table } 5 \text {. } \\
\text { Hypotheses testing } \\
\text { results }\end{array}$} & H12d: Neuroticism $\rightarrow$ Alertness $\rightarrow$ Intention & -0.333 & 0.739 \\
\hline & H12e: Openness $\rightarrow$ Alertness $\rightarrow$ Intention & 4.382 & $0.000^{* * *}$ \\
\hline & Notes: **Significant at $1 \%$; *significant at $5 \%$ & & \\
\hline
\end{tabular}

The current study results revealed that personality traits such as conscientiousness and openness to new experiences tend to be the only personality constructs associated with entrepreneurial intention. Contrary to neuroticism, agreeableness and extraversion, which did not represent a significant impact on entrepreneurial intentions. This result is consistent with the meta-analysis conducted by Zhao and Seibert (2006). Furthermore, the study found that extraversion and openness to new experiences tend to be the only personality constructs associated with entrepreneurial alertness. In contrast, conscientiousness, extraversion and neuroticism did not represent a significant impact on entrepreneurial alertness. Openness to experience was the only personality construct associated with both entrepreneurial alertness and entrepreneurial intention, while agreeableness and neuroticism appear to be unrelated to either outcome.

Openness to experience has a positive impact on student's entrepreneurial intentions. The more the student was curious and imaginative, the more likely they are to start a new business. It means that students who score high on this trait will have a high intention to become entrepreneurs. In other words, students who are highly creative, open to trying new things and enjoy dealing with new challenges will have a high level of intention to become entrepreneurs and are more likely to create their venture in the future. They also tend to have a wide range of interests and a high degree of curiosity about things and the people around them, learn new things and enjoy new experiences.

The current finding supports the previous studies which argued that exploring new ideas, being creative and taking novel approaches were essential for starting a new venture (Zhao et al., 2010; Antoncic et al., 2015; Zhao and Seibert, 2006; Brice, 2004; Butz et al., 2018; Murugesan and Jayavelu, 2017; Liang et al., 2015).

Also, the results are consistent with several previous studies that argue that individuals with a high level of conscientiousness who are well organized, responsible and dependable are more likely to create their own business in the future. The current finding supports the previous studies, which argued that the more the student was thoughtfulness, reasonable impulse control and goal-directed behaviors, the more he or she is likely to start a new business (Brice, 2004; Zhao et al., 2010; Liang et al., 2015; Antoncic et al., 2015; Zhao and Seibert, 2006; Butz et al., 2018). 
On the other hand, the study results show that traits as extraversion, agreeableness and neuroticism are invaluable in understanding entrepreneurial intention among Jordanian university students. The current finding supports the previous studies which argued: extraversion (Zhao and Seibert, 2006; Brice, 2004; Butz et al., 2018; Tuncer and Şahin, 2018; Jusoh and Chinna, 2019; Maldonado, 2018; Purwana et al., 2018), agreeableness (Zhao et al., 2010; Antoncic et al., 2015; Butz et al., 2018; Tuncer and Şahin, 2018; Murugesan and Jayavelu, 2017; Purwana et al., 2018; Liang et al., 2015) and neuroticism (Antoncic et al., 2015; Brice, 2004; Tuncer and Şahin, 2018; Maldonado, 2018; Liang et al., 2015) have no association with individuals' entrepreneurial intentions. There is a need to further studies to explain these results.

This study may be one of a few studies, which has identified a strong relationship between entrepreneurial alertness and entrepreneurial intention based on the theory of planned behaviors. Students who possess a higher level of alertness can better process information and identify a business opportunity. High alertness to information increases the student's confidence toward achieving goals, and hence entrepreneurial alertness worked through perceived behavioral control leading to higher intention. Our findings are consistent with the findings of Martin et al. (2013). These findings indicate that if a person is alert, then the chance to start his own business is greater for exploiting the chance. Students who score high levels of entrepreneurial alertness will report a higher level of entrepreneurial intention. In other words, entrepreneurial alertness stimulating the desire for entrepreneurial intention.

Results revealed that only openness to experiences and extraversion impact entrepreneurial intentions, while conscientiousness, neuroticism and agreeableness have no indirect impact on entrepreneurial intention. An extraverted student who is sociable, outgoing, risk-taker and enthusiastic is an information seeker and ready to exchange information with others to gain new ideas that support his decision to open his own business in the future. The openness of experience is also a great indicator for students who have great creativity, hard work and ready to gather information from different resources to seek a good chance and keep their eyes out for new ideas to establish their firm. No previous studies were found to confirm these results because of the lack of researches in this field. This study contributes to other researchers because the findings and the results will stimulate others to conduct future studies investigating the mediating role of alertness between the Big Five personality traits and entrepreneurial intention.

\section{Conclusions}

From a practical point of view, countries and organizations that do not have a sufficient budget to encourage entrepreneurship with accelerator or incubator models now have a starting point to strengthen the entrepreneurial mindset as an initial phase through people's entrepreneurial intentions. University educators can adapt tools to their teaching curricula that provide the development of personalities related to entrepreneurial intention (conscientiousness and openness to experience). This study sheds light on the importance of the conscientiousness trait to enhance entrepreneurial intention; universities can develop student's skills for this trait by establishing new programs and activities to maintain a strong sense of responsibility which promotes their dependability at work. This study also confirms the strong positive impact of openness to experience on entrepreneurial intention; universities should improve their creativity and imaginative skills by making competitions between students with new ideas or future projects. The current study shows the importance of entrepreneurial alertness as a strong indicator of entrepreneurial intentions. Students in universities should be taught how to collect information to seek opportunities surrounding them. 
APJIE 15,1

This knowledge may help Jordanian universities that are responsible for developing entrepreneurship concepts, especially in developing countries like Jordan that suffer from unemployment issues. We recommend that more research in this specific area be done. Future studies may explore whether there is a difference between the personality factors found in entrepreneurial intention versus the personality factors of individuals who currently have careers as entrepreneurs. Also, future studies may carry out longitudinal studies within groups exposed to programs that develop skills and personalities related to entrepreneurial intention.

Based on the study results, some future research recommendations include: first, researchers can collect samples from business students who have excessive knowledge of entrepreneurship and risk starting the initiative. Second, future researchers can lead investigation by other personality attributes. Third, researchers might replicate the study by improving the sample size and using the probability sampling technique. Fourth, researchers can identify potential mediators which could affect the relationship between personality traits and entrepreneurial intentions. Potential mediating variables include culture, age, group, selfefficacy and loss aversion bias which future researchers might use in their studies.

\section{References}

Alkhatib, K., Al-Aiad, A., Mustafa, M. and Alzubi, S. (2020), "Impact factors affecting entrepreneurial intention of Jordanian private universities students: a mediation analysis of perception toward entrepreneurship", Sustainable and Energy Efficient Computing Paradigms for Society, Springer, Cham, pp. 53-65.

Antoncic, B., Bratkovic Kregar, T., Singh, G. and DeNoble, A.F. (2015), "The big five personalityentrepreneurship relationship: evidence from Slovenia”, Journal of Small Business Management, Vol. 53 No. 3, pp. 819-841.

Barrick, M.R., Mount, M.K. and Judge, T.A. (2001), "Personality and performance at the beginning of the new millennium: what do we know and where do we go next?", International Journal of Selection and Assessment, Vol. 9 Nos 1/2, pp. 9-30.

Brice, J. (2004), "The role of personality dimensions on the formation of entrepreneurial intentions", USASBE Small Business Advancement National Center, University of Central AR.

Butz, N.T., Hanson, S., Schultz, P.L. and Warzynski, M.M. (2018), "Beyond the big five: does grit influence the entrepreneurial intent of university students in the US?", Journal of Global Entrepreneurship Research, Vol. 8 No. 1, pp. 1-16.

Chhabra, S., Raghunathan, R. and Rao, N.V.M. (2020), "The antecedents of entrepreneurial intention among women entrepreneurs in India", Asia Pacific Journal of Innovation and Entrepreneurship, Vol. 14 No. 1, pp. 76-92.

Ciavarella, M.A., Buchholtz, A.K., Riordan, C.M., Gatewood, R.D. and Stokes, G.S. (2004), “The big five and venture survival: is there a linkage?", Journal of Business Venturing, Vol. 19 No. 4, pp. 465-483.

Costa, P.T. and McCrae, R.R. (1992), Neo Personality Inventory-Revised (NEO PI-R), Psychological Assessment Resources, Odessa, FL.

Farrukh, M., Alzubi, Y., Shahzad, I.A., Waheed, A. and Kanwal, N. (2018), "Entrepreneurial intentions: the role of personality traits in perspective of theory of planned behaviour", Asia Pacific Journal of Innovation and Entrepreneurship, Vol. 12 No. 3, pp. 399-414.

Fiske, S.T., Gilbert, D.T. and Lindzey, G. (Eds) (2010), Handbook of Social Psychology, Vol. 1, John Wiley and Sons.

Goldberg, L.R. (1993), “The structure of phenotypic personality traits”, American Psychologist, Vol. 48 No. 1, pp. 26-34. 
Hair, J.F., Jr, Sarstedt, M., Ringle, C.M. and Gudergan, S.P. (2017), Advanced Issues in Partial Least Squares Structural Equation Modeling, SAGE publications.

Huang, C. (2016), An Empirical Study on the Relationship between Entrepreneurial Personality Traits, Entrepreneurial Alertness and Entrepreneurial Opportunity Identification, Anhui University of Finance and Economics, Bengbu.

Jusoh, M. and Chinna, K. (2019), "Impact of big five personality traits on entrepreneurial intention of engineering undergraduates", Research in Business and Management, Vol. 6 No. 2, pp. 35-44.

Kaish, S. and Gilad, B. (1991), "Characteristics of opportunities search of entrepreneurs versus executives: sources, interests, general alertness”, Journal of Business Venturing, Vol. 6 No. 1, pp. $45-61$.

Kerr, S.P., Kerr, W.R. and Xu, T. (2018), "Personality traits of entrepreneurs: a review of recent literature", Foundations and Trends® in Entrepreneurship, Vol. 14 No. 3, pp. 279-356.

Kim, S. (2018), "Domains and trends of entrepreneurship research", Management Review: An International Journal, Vol. 13 No. 1, pp. 65-90.

Kirzner, I.M. (1999), “Creativity and/or alertness: a reconsideration of the schumpeterian entrepreneur", The Review of Austrian Economics, Vol. 11 Nos 1/2, pp. 5-17.

Knoema (2019), "Jordan - global entrepreneurship index", available at: https://knoema.com/atlas/ Jordan/topics/World-Rankings/World-Rankings/Global-entrepreneurship-index

Liang, C.-T., Chia, T.-L. and Liang, C. (2015), "Effect of personality differences in shaping entrepreneurial intention", International Journal of Business and Social Science, Vol. 6 No. 4.1, pp. 166-176.

Lim, W., Mohar, Y. and Leilanie, M. (2017), “The impact of entrepreneurial alertness on entrepreneurial intention among university students in Malaysia: theory of planned behavior", Journal of Engineering and Applied Sciences, Vol. 12, pp. 1409-1418.

Lu, H. and Wang, J. (2018), "Entrepreneurial intention of two patterns of planned behaviour and alertness: empirical evidence in China", The Journal of Asian Finance, Economics and Business, Vol. 5 No. 2, pp. 63-72.

Maldonado, R.G.H. (2018), "Entrepreneurial intention: is it influenced by personality and gender factors?", Revista Academia and Negocios, Vol. 4 No. 2, pp. 1-12.

Martin, B.C., McNally, J.J. and Kay, M.J. (2013), "Examining the formation of human Capital in entrepreneurship: a meta-analysis of entrepreneurship education outcomes", Journal of Business Venturing, Vol. 28 No. 2, pp. 211-224.

Merrill, J.S., Chambers, T.M. and Roberts, W.A. (2008), "Associations and barriers to intrapreneurship and entrepreneurship", Management Review: An International Journal, Vol. 3 No. 1, pp. 4-22.

Miralles, F., Giones, F. and Riverola, C. (2016), "Evaluating the impact of prior experience in entrepreneurial intention", International Entrepreneurship and Management Journal, Vol. 12 No. 3, pp. 791-813.

Murugesan, R. and Jayavelu, R. (2017), "The influence of big five personality traits and self-efficacy on entrepreneurial intention: the role of gender", Journal of Entrepreneurship and Innovation in Emerging Economies, Vol. 3 No. 1, pp. 41-61.

Purwana, D., Suhud, U. and Wibowo, A. (2018), "Big-five personality of tertiary students and entrepreneurial intention”, Advanced Science Letters, Vol. 24 No. 10, pp. 7180-7183.

Quan, X. (2012), "Prior experience, social network, and levels of entrepreneurial intentions", Management Research Review, Vol. 35 No. 10, pp. 945-957.

Saeed, R., Mussawar, S., Lodhi, R.N., Iqbal, A., Nayab, H.H. and Yaseen, S. (2013), "Factors affecting the performance of employees at the workplace in the banking sector of Pakistan”, Middle East Journal of Scientific Research, Vol. 17 No. 9, pp. 1200-1208. 
APJIE 15,1

Singh, G. and DeNoble, A. (2003), "Views on self-employment and personality: an exploratory study", Journal of Developmental Entrepreneurship, Vol. 8 No. 3, pp. 265-281.

Tang, J., Kacmar, K.M.M. and Busenitz, L. (2012), "Entrepreneurial alertness in the pursuit of new opportunities", Journal of Business Venturing, Vol. 27 No. 1, pp. 77-94.

Tuncer, B. and Şahin, F. (2018), "Big five personality traits and entrepreneurial intention: the moderating role of social valuation", International Conference of Applied Business and Management, Porto, Portekiz.

Van Gelderen, M., Thurik, R. and Bosma, N. (2006), "Success and risk factors in the pre-startup phase", Small Business Economics, Vol. 26 No. 4, pp. 319-335.

Verheul, I., Thurik, R., Grilo, I. and Van der Zwan, P. (2012), "Explaining preferences and actual involvement in self-employment: gender and the entrepreneurial personality", Journal of Economic Psychology, Vol. 33 No. 2, pp. 325-341.

Wang, J.-H., Chang, C.-C., Yao, S.-N. and Liang, C. (2016), "The contribution of self-efficacy to the relationship between personality traits and entrepreneurial intention”, Higher Education, Vol. 72 No. 2, pp. 209-224.

Woo, H.R. (2018), "Personality traits and intrapreneurship: the mediating effect of career adaptability", Career Development International, Vol. 23 No. 2, pp. 145-162.

Yan, X., Gu, D., Liang, C., Zhao, S. and Lu, W. (2018), "Fostering sustainable entrepreneurs: evidence from China college students' 'internet plus' innovation and entrepreneurship competition (CSIPC)", Sustainability, Vol. 10 No. 9, pp. 1-23.

Zhao, H. and Seibert, S.E. (2006), "The big five personality dimensions and entrepreneurial status: a Meta-analytical review", Journal of Applied Psychology, Vol. 91 No. 2, pp. 259-271.

Zhao, H., Seibert, S.E. and Lumpkin, G.T. (2010), "The relationship of personality to entrepreneurial intentions and performance: a meta-analytic review", Journal of Management, Vol. 36 No. 2, pp. 381-404.

\section{Corresponding author}

Mohammad Suleiman Awwad can be contacted at: awwad@mutah.edu.jo

For instructions on how to order reprints of this article, please visit our website: 